\title{
Controlling Energy Consumption by Internet of Things (IoT) Applications
}

\author{
Asim Majeed ${ }^{\# 1}$, Rehan Bhana ${ }^{* 2}$, Shaheed Parvez ${ }^{* 3}$ \\ Birmingham City University, UK \\ ${ }^{\# 1}$ Asim.Majeed@bcu.ac.uk, ${ }^{* 2}$ Rehan.Bhana@bcu.ac.uk, ${ }^{* 3}$ Shaheed.Parvez@bcu.ac.uk
}

\begin{abstract}
The concept of Internet-of-Things (IoT) emerged around two decades ago but has gained momentum during the last few years. The modern technology has infused this innovative paradigm on several scales but still lacks shadowing many aspects of our daily life. Several businesses have attempted its interjection in their processes, however, some of the features of IoT have been avoided by most of them due to its cryptic nature and requiring technical skills prior to its replete use. The development of IoT is well ahead of its need to be and linked to an inability of adopting its fast-paced changes along with the lack of strong business operational models. This paper contributes to the developing of a smart home where electrical appliances would react according to the environment while users would be able to control them through smart gadgets. The conventional setup of arranging and organising the electrical appliances is compared to the newly-developed, several patterns have been observed through which carbon footprints and electricity consumption could be reduced. The collected data has been analysed and it proves that IoT does not only helps save energy consumption but also to save the environment. This paper also highlights the challenges faced by consumers who are affected by the penetration of IoT into their lives along with benefits of infusing IoT applications. The overall theme of this paper is, therefore, to make the consumer understand the benefits of IoT applications into their lives using Arduino setup to control electrical home appliances as a benchmark.
\end{abstract}

Keywords- IoT, Energy, Applications, Arduino, Consumption.

\section{INTRODUCTION}

The Dot-Com boom brought the concept of Internet of Things (IoT) but evidently was unable to make any notable impacts on the environment as well as making homes smart [5]. The IoT could have been infused and incorporated rigorously within homes to develop smart homes. The automation of few things in the home does not constitute the theory of smart home but in actual establishing the connection of various devices with the computer through internet refers to the equilibrium of IoT applications. When referring to the word of IoT, it details about a diverse range of things contradicting the homogenous discipline which bridges the gap between the digital world and the physical world resulting development of a smart environment [4]. The IoT acts like a live wire medium between sensors, devices and the internet which gives the devices around you an ability to think, get connected, producing big data, analysing it and converting this manual information to automation seamlessly and consequently making homes smarter through machines sensing the environments and responding accordingly [11].

Several thoughts have been linked with the term "Smart" as it means differently to different people. The prime theme is to understand this term before forming the foundations of IoT. Any process automating the tasks and reducing human efforts is termed as "Smart". There is a diverse range of hardware is available in the market which helps reducing human efforts and in this paper, we talk about Arduino, which is based on IoT paradigm which gives power to the user to build any stuff of their choice [8]. Obviously, the process of creating new products using Arduino leads to some problems which we would discuss a later section of this paper. The formation and application of IoT are flexible in several ways, such as a plan of it application could be well laid out before the house is built and in another way, it could be infused within the existing home infrastructure [2].

It is evident that the IoT applications are numerous and could cover every sphere of human life effectively translating the human effort to sophisticated automation. This transformation requires the writing of a piece of computer code and since not everyone could write this, it affects the derivatives and target audience of IoT market [10]. This drawback leaves the interest in IoT applications only for those who could programme, leaving a huge gap in using IoT applications for users who wanted to have a freedom of creating and developing new automated things to reduce their efforts. The brink of 21 st century has escalated the companies to fill this gap utilising IoT application making modern homes smarter in several ways, such as:

- Smoke detection in the environment and alerting users

- Security cameras automation and controlling using phones

- Controlling electric appliances using internet and smartphones

- Distance measurement before starting journey

- Medical diagnosis and prescription advise systems

Although the modern companies have invested a lot in IoT application but failed to tract attraction even signifying the 
importance of IoT applications for users [9]. The IoT integration entails several challenges in the modern day living styles unless common people are educated about IoT and how it would affect their lives benefitting financially and environmentally. This exposure would leave no choice for common people to be compelled [2].

This paper is divided into 4 sections whereas the first section depicts the setup of Arduino with electrical appliances and making them react according to the environment changes. The second section describes how IoT could help reducing human effort, electricity energy consumption and how it would be helpful for the environment purposes. The third part discusses the challenges faced by IoT applications, not only by the organisations but also at the user level. The fourth section describes the usefulness of implementing IoT applications for saving people's lives. All these sections are Arduino based and how this could be used to create IoT paradigm, helping users and how to mature various challenges and this section is about conclusion.

\section{ARDUINO SETUP}

The internet connection is used to connect Arduino with a computer and USB power supply is used to provide electricity. The environment condition is sensed through two sensors (Temperature Sensor and Motion Sensor) fitted on Arduino [5]. The humidity and temperature are measured through the Temperature sensor whereas the change in infrared levels in the environment is read by the Motion sensor. The Temperature sensor is connected to Arduino with 3.3 V, GND and D7 pin and Motion sensor with 5 V, GND and D10 pin. To turn ON and OFF the load, two relays are integrated into a "Closed" mode [8].

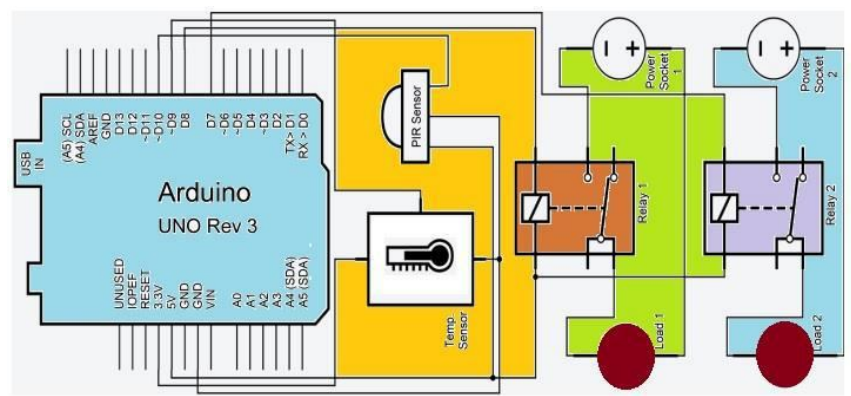

Figure 1: Arduino Setup for Smart Home Development

The lighting source is linked to Load 1, such as fluorescent lamp or a bulb. On the other hand, controlling of temperature is associated with Load 2 which could be known as a fan who do not provide default controlling facility for temperature. Both loads have two ends in which one end goes into Relay and the other goes directly into the Power Socket. This arrangement would also users of these appliances to control them through smartphones if they are connected to the internet [4]. The current states of both the relays are read on the website by the software designed in Integrated Development Environment (IDE). The software is specially programmed for this purpose which sends the relevant commands and instructions to Arduino for processing. Both the sensors are being checked continuously by Arduino ensuring inputs and turning ON motion sensors if they detect any movement or change in the environment. The Load 2 gets to OFF state if the temperature goes below 18 Centigrade and changes its state to $\mathrm{ON}$ as soon as the temperature goes above 18 Centigrade [3]. The designed setup is the very simple ignition of making our homes Smart and on this basis, we can control the electrical appliances in our home as soon as they sense any change in their respective environments. The above model in figure 1 does not only help us understanding the control of appliances through internet but also provide us with an understanding of electricity consumption pattern in an average house [6]. This forms the argument of how IoT applications could help us save energy and this paradigm could be beneficial for the environment [1].

\section{EXPERIMENTS, SEMANTICS AND RESULTS}

The Arduino is used to carry out the experiments instead of even several other programmable boards are available in the market [9]. The microcontroller ATMega328P is chipped in Arduino Uno which makes experiments results as sensitive as possible, collecting in detail information and reacting to it. Various equipment's are used to carry out these experiments ensuring all necessary safety precaution. These experiments have provided us readings on various occasions quantifying the usage of energy consumptions over a specific period of time. This experiment outcome would justify the usage of IoT applications in our daily lives and reduce carbon footprints as well as save energy.

Table 1: DATA COLLECTED OVER A PERIOD OF 6 WEEKS

\begin{tabular}{|c|c|c|c|c|c|c|}
\hline & Week 1 & Week 2 & Week 3 & Week 4 & Week 5 & Week 6 \\
\hline & Without & $\begin{array}{l}\text { With lot } \\
\text { Setun }\end{array}$ & $\begin{array}{l}\text { Without } \\
\text { lot Setun }\end{array}$ & $\begin{array}{l}\text { With loT } \\
\text { Setup }\end{array}$ & $\begin{array}{l}\text { Without } \\
\text { Withetur }\end{array}$ & $\begin{array}{l}\text { With loT } \\
\text { Setur }\end{array}$ \\
\hline \multirow[t]{3}{*}{ (Bulb) Consuming $20 \mathrm{~W}$} & $\begin{array}{l}\text { Hours } \\
\text { Used: } \\
126.3\end{array}$ & $\begin{array}{l}\text { Hours Used: } \\
106.8\end{array}$ & $\begin{array}{l}\text { Hours } \\
\text { Used: } \\
122.7\end{array}$ & $\begin{array}{l}\text { Hours } \\
\text { Used: } \\
104.6\end{array}$ & $\begin{array}{l}\text { Hours } \\
\text { Used: } \\
115.2\end{array}$ & $\begin{array}{l}\text { Hours } \\
\text { Used: } \\
103.2\end{array}$ \\
\hline & $\begin{array}{l}\text { Units } \\
\text { Used: } 5.3\end{array}$ & $\begin{array}{l}\text { Units Used: } \\
4.2\end{array}$ & $\begin{array}{l}\text { Units } \\
\text { Used: } 4.8\end{array}$ & $\begin{array}{l}\text { Units } \\
\text { Used: } 4.3\end{array}$ & $\begin{array}{l}\text { Units } \\
\text { Used: } 4.7\end{array}$ & $\begin{array}{l}\text { Units } \\
\text { Used: }\end{array}$ \\
\hline & & & & & & \\
\hline \multirow{4}{*}{$\begin{array}{l}\text { (Temperature Control) } \\
\text { Consuming } 160 \mathrm{~W}\end{array}$} & Hours & Hours Used: & Hours & Hours & Hours & Hours \\
\hline & $\begin{array}{l}\text { Used: } \\
145.8\end{array}$ & & $\begin{array}{l}\text { Used: } \\
137.2\end{array}$ & $\begin{array}{l}\text { Used: } \\
80.8\end{array}$ & Used:129.4 & $\begin{array}{l}\text { Used: } \\
75.3\end{array}$ \\
\hline & Units & Units Used: & Units & Units & Units & Units \\
\hline & Used: 25.5 & 15.5 & Used: 22.3 & $\begin{array}{l}\text { Used: } \\
13.7\end{array}$ & Used: 21.1 & $\begin{array}{l}\text { Used: } \\
12.2\end{array}$ \\
\hline $\begin{array}{l}\text { Total Units Consumed from both } \\
\text { the appliances }\end{array}$ & 30.6 & 18 & 27.1 & 17.2 & 26.9 & 16.8 \\
\hline
\end{tabular}

The results were gathered over a six-week period using the designed IoT setup on alternative weeks so to avoid any potential discrepancies (Table 1). The alternative weeks (1st, 3rd and 5th) were left without the IoT setup but Loads used for any numbers of hours during these days were collected by Arduino. The Arduino was programmed in a way that it would collect all the information without interfering the actual circuit. All other weeks (2nd, 4th and 6th) were connected with the IoT designed circuit. The generated results during these weeks depict that the energy consumed by Load 2 was far less than the other weeks (1st, 3rd and 5th). Almost 44\% decreased in units consumed by Load 2 . For Load 1, energy unit consumption was not much less but still showed $13 \%$ reduction. This is not too much in terms of percentage but still, goes in the favour if someone's energy consumption is too high and this setup would help to restore fewer expenses. The reduction is carbon footprints is directly proportional to the usage of electricity energy consumption 
and in the current scenario exploits the decrease in carbon footprints.

It is estimated that almost 2 pounds of Carbon dioxide are produced for every 1-Kilowatt hour of energy. So without using the IoT set up it generates the 59 pounds of Carbon dioxide. This consumption could be avoided if IoT set is used only on two appliances (in the current scenario). As soon as IoT set is applied to the current scenario, the carbon footprints dropped down to 36 pounds resulting in a reduction of 23 pounds carbon footprints [5]. As this experiment is based only considering two appliances so all energy consumption or saving is based on those. The gathered results from two appliances represent that a simple framework of IoT setup can reduce carbon footprints as well as electricity bill. This setup is worth for those who tend to leave lights switched on while they go out of homes as this timeframe could get longer unexpectedly [7]. If appliances are engaged through IoT setup associated with motion sensors, they would automatically sense the IR levels and if there is no movement, lights would be switched off consequently reducing energy consumption. The opposite process would ignite if someone enters the room.

The products like Raspberry Pi and Arduino are easy and have the flexibility to be coded to automate the processes the way the society want [2]. A lot of people in the society do not have the fundamental knowledge of coding so unable to programme these devices for their best usage [7]. The sector of the society who is unable to manage this is targeted by the technological companies so to fill up the gap. This gap facilitates the companies to build their own smart devices so to make homes smarter. Several hi-tech companies such as Intel, HP, Samsung and etc. has launched their products allowing consumers to make the processes automate [8]. This innovation is not just limited to automate the processes but also executes the instruction as soon as a certain behaviour is sensed. It is doubtless that the integration of IoT paradigm has made homes smarter but it still keeps challenges which are hindered and does not fully facilitates the deeper association normal lives [7].

\section{FUTURE OF IOT BASED ON ARDUINO}

The IoT applications have a wider scope in our lives and eventually would cover every aspect of it. The experiment above has briefed that the home appliances could be controlled from anywhere and they could be made smart enough to reach according to their respective situations. While talking about a fully automated and a smart home, several things could interact with each other to generate the data and analyse on the basis to react through a better automation [1]. There could be some emergencies in the home but if they are neglected during interconnectivity or coding the IoT applications, all efforts would be useless. Several types of sensors form the IoT infrastructure and using reliable sensors we could move to developing the health checking applications of humans, choosing your own choice doctor, understanding the current state of the body [10]. If the body state is unwell, it would call the ambulance automatically and any other required action could be taken by the doctor. The conceptual implementation of IoT may seem a bit of a fiction at this stage but quite a few sensors have been developed which monitors the heart rate, current location, body temperature and breathing pattern. Moreover, all the said information can be collected through a smart watch [8]. The collection of data is possible through the sensors, so we can transmit that to our doctor which can contribute in lessening the deaths due to hear attack and etc. This data could be analysed by the doctor to carry out some actions before any mishaps occur [11].

Within the new houses, several new aspects of automation could be implemented, such as complete removal of physical switches. This scenario would be very interesting as all appliances would be connected to IoT-based sensors. The lights, fans and temperature controls could be attached to sensors and they can turn ON and OFF as per the environment changes [8]. The development of Smart homes has gone to a stage where these appliances are powered to think and decide when to turn ON and Switch OFF. The ideal formation of Smart homes based on IoT paradigm, the smart watch will sense you are awake, coffee make would turn ON, curtains would be removed automatically and a nice background music would play by the time [3].

\section{Conclusion}

The concept of associating sensors, computers and devices has been around our lives from last few decades but the modern living demands for technological advancements have ushered the confluence of real-time applications of IoT paradigm. The prime theme behind IoT is to revolutionise and making an interconnected and a smart world building strong and interconnected relationships among devices as well as objects. This innovation would intertwine the livings of modern day people providing the fully automated environment. The IoT would eventually change the thinking styles of people including ramifications of potential challenges within its applications. This paper has identified that how Arduino could have been used to save energy consumption which provides a cheap solution for a common living man. This innovation could lead to several challenges such as rights and issues, regulatory, legal, standards and interoperability, privacy and security. To maximize the benefits of IoT the above challenges needed to be addressed to reduce the risks which involves the evolving set of complex and expensive technological advancements.

\section{REFERENCES}

[1] Alam, M.R.; Alauddin, M.A. A review of smart homes-past, present, and future. IEEE Trans. Syst. Man Cybern. C Appl. Rev. 42, 1190-1203, 2012.

[2] Ferguson, T., Have Your Objects Call My Object. Harvard Business Review, June, 1-7, 2002. 
[3] Fleming, B. Advances in automotive electronics (automotive electronics). IEEE Veh. Technol. Mag. 9, 4-19, 2014.

https://doi.org/10.1109/MVT.2014.2360640

[4] Graditi, G.; Ippolito, M.G.; Lamedica, R.; Piccolo, A.; Ruvio, A.; Santini, E.; Siano, P.; Izzo, G. Innovative control logics for a rational utilization of electric loads and air-conditioning systems in a residential building. Energy Build. 102, 1-17, 2015.

https://doi.org/10.1016/j.enbuild.2015.05.027

[5] Khattak, A.M., Pervez, Z., Jehad Sarkar, A.M., and Lee, Y., "Service Level Semantic Interoperability," 2010 10th IEEE/IPSJ International Symposium on Applications and the Internet, saint, pp. 387-390, 2010.

https://doi.org/10.1109/SAINT.2010.54

[7] Mars, M. Telemedicine and advances in urban and rural healthcare delivery in africa. Prog. Cardiovasc. Dis. 56, 326-335, 2013.Moeinfar, D., Shamsi, H. and Nafar, F., Design and Implementation of a Low-Power Active RFID for Container Tracking @ $2.4 \mathrm{GHz}$ Frequency: Scientific Research, 2012.

[8] Sah, P., Saving Environment Using Internet of Things: Challenges and the Possibilities. Advances in Internet of Things, 6, 55-64, 2016.https://doi.org/10.4236/ait.2016.64004

[9] Sun, C., Application of RFID Technology for Logistics on Internet of Things, 2012.

[10] Wade, V.; Soar, J.; Gray, L. Uptake of telehealth services funded by medicare in australia. Aust. Health Rev. 38, 528-532, 2014.

https://doi.org/10.1071/AH14090

[11] Xu, L.D.; He, W.; Li, S. Internet of things in industries: A survey. IEEE Trans. Ind. Inform. 10, 2233-2243, 2014.

https://doi.org/10.1109/TII.2014.2300753

[12] Yu, L.; Lu, Y.; Zhu, X. Smart hospital based on internet of things. J. Netw. 7, 1654-1661, 2012.

https://doi.org/10.4304/jnw.7.10.1654-1661 